\title{
SOME PROPERTIES OF FUZZY NORMED LINEAR SPACES AND FUZZY RIESZ BASES
}

\author{
BAYAZ DARABY, FATANEH DELZENDEH, and ASGHAR RAHIMI
}

\begin{abstract}
Some results of fuzzy frames on fuzzy Hilbert spaces from the point of view of Bag and Samanta are proved. In this paper, we define dual fuzzy frames and fuzzy Riesz bases and establish some fundamental results via dual fuzzy frames and fuzzy Ries bases. Next, we investigate the relation between fuzzy frame and fuzzy Riesz bases.
\end{abstract}

MSC 2010. 30C45.

Key words. Fuzzy normed linear space, fuzzy Riesz base.

\section{REFERENCES}

[1] T. Bag and S.K. Samanta, Fuzzy bounded linear operators, Fuzzy Sets and Systems, 151 (2005), 513-547.

[2] T. Bag and S.K. Samanta, Finite dimensional fuzzy normed linear spaces, Ann. Fuzzy Math. Inform., 6 (2013), 271-283.

[3] I. Beg and K. Mahmood Aamir, Fuzzy wavelets, The Journal of Fuzzy Mathematics, 21 (2013), 623-638.

[4] R. Biswas, Fuzzy inner product spaces and fuzzy norm functions, Inform. Sci., 53 (1991), 185-190.

[5] S.C. Cheng and J. N. Mordeson, Fuzzy linear operators and fuzzy normed linear spaces. In: First International Conference on Fuzzy Theory and Technology Proceedings, Abstracts and Summaries, 1992, pp. 193-197.

[6] O. Christensen, An introduction to frames and Riesz bases, Birkhäuser, Basel, 2003.

[7] B. Daraby, Z. Solimani and A. Rahimi, A note on fuzzy Hilbert spaces, Journal of Intelligent \& Fuzzy Systems, 31 (2016), 313-319.

[8] B. Daraby, Z. Solimani and A. Rahimi, Some properties of fuzzy Hilbert spaces, Complex Anal. Oper. Theory., 11 (2017), 119-138.

[9] I. Daubechies, Ten Lectures on Wavelets, SIAM, Philadelphia, 1992.

[10] I. Daubechies, A. Grossmann and Y. Meyer, Painless nonorthogonal expansions, J. Math. Phys., 27 (1986), 1271-1283.

[11] R.J. Duffin and A.C. Schaeffer, A class of nonharmonic Fourier series, Trans. Amer. Math. Soc., 72 (1952), 341-366.

[12] A.M. El-Abyad and H.M. El-Hamouly, Fuzzy inner product spaces, Fuzzy Sets and Systems, 44 (1991), 309-326.

The authors are grateful to the referees for their valuable suggestions in rewriting the paper in the present form.

DOI: $10.24193 /$ mathcluj.2019.2.02 
[13] C. Felbin, Finite dimensional fuzzy normed linear spaces, Fuzzy Sets and Systems, 48 (1992), 239-248.

[14] A. Hasankhani, A. Nazari and M. Saheli, Some properties of fuzzy Hilbert spaces and norm of operators, Iran. J. Fuzzy Syst., 7 (2010), 129-157.

[15] A.K. Katsaras, Fuzzy topological vector spaces II, Fuzzy Sets and Systems, 12 (1984), $143-154$

[16] P. Majumdar and S.K. Samanta, On fuzzy inner product spaces, Fuzzy Mathematics, 16 (2008), 377-392.

[17] S. Mukherjee and T. Bag, Some properties of fuzzy Hilbert spaces, International Journal of Mathematics and Computing, 1 (2011), 50-56.

[18] A. Popoola, S. Ahmad and K. Ahmad, A fuzzy-wavelet method for analysing nonstationary time series. In: RASC 2004; 5th International Conference on Recent Advances in Soft Computing, Nottingham, United Kingdom, 2004, pp. 231-236.

Received February 10, 2018

Accepted December 17, 2018
University of Maragheh Department of Mathematics Maragheh, Iran

E-mail: bdaraby@maragheh.ac.ir

E-mail: fatenehdelzende@yahoo.com

E-mail: rahimi@maragheh.ac.ir 